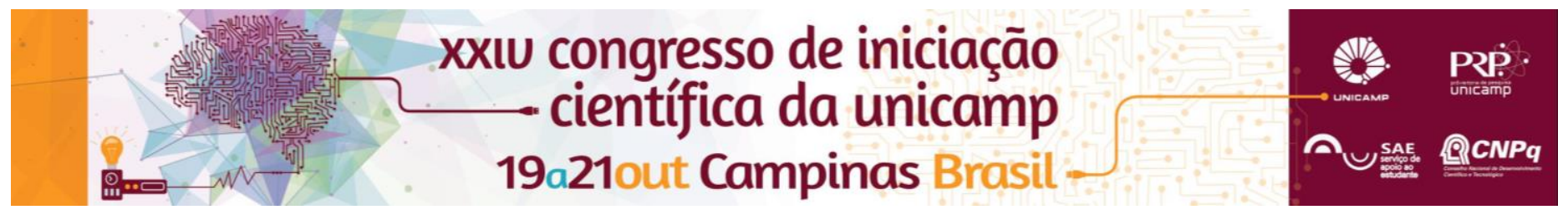

\title{
Desenvolvimento e caracterização de filmes lipídico-biopoliméricos funcionais para liberação transdérmica de lidocaína
}

\author{
Bárbara O. De Paula*, Lígia N. M. Ribeiro, Eneida de Paula.
}

\begin{abstract}
Resumo
A anestesia tópica transdérmica é de grande importância na minimização da dor prévia aos procedimentos clínicos dolorosos ou lesões superficiais. O presente trabalho objetiva o desenvolvimento de formulações de carreadores lipídicos nanoestruturados (CLN), compostos por manteiga de Karité e óleo de amêndoas, como matriz lipídica funcional das nanopartículas. As formulações foram avaliadas quanto ao tamanho de partículas, índice de polidispersividade, potencial Zeta e $\mathrm{pH}$, por 120 dias a $25^{\circ} \mathrm{C}$; eficiência de encapsulação de lidocaína (2\%) e morfologia das partículas (por microscopia eletrônica de transmissão). Todas as formulações mantiveram-se estruturalmente estáveis ao longo do tempo. A formulação com a maior eficiência de encapsulação ( 86\%) foi incorporada em matrizes biopoliméricas de quitosana, alginato e xantana, sendo processadas como filmes. Os filmes lipídico-biopoliméricos para liberação transdérmica de lidocaína (2\%) deverão ser avaliados quanto à capacidade de absorção de água e pelo teste in vitro de liberação de fármacos. Assim, propomos uma estratégia nanobiotecnológica viável, de baixo custo e reprodutível, que permitirá o desenvolvimento de um sistema transdérmico de liberação de lidocaína com propriedades melhoradas.
\end{abstract}

Palavras-chave: liberação sustentada, carreadores lipídicos nanoestruturados, biopolímeros.

\section{Introdução}

A anestesia tópica minimiza a sensação dolorosa cutânea associada a vários procedimentos médicos e em lesões epidérmicas. $O$ estrato córneo estratificado representa a principal barreira fisiológica que impede a eficiente absorção dos fármacos aplicados topicamente ${ }^{1}$. Os carreadores lipídicos nanoestruturados (CLN) são sistemas formados por uma matriz lipídica composta por lipídios sólidos e líquidos à temperatura ambiente, mais surfactante. Sua aplicação em pele é especialmente atraente graças à elevada área superficial das nanopartículas, que permite maior contato com o estrato córneo e penetração de moléculas bioativas no sítio-alvo, além de liberação sustentada das mesmas ${ }^{2}$. O uso de excipientes naturais no preparo de CLN fornece vantagem adicional ao sistema. Por outro lado, o desenvolvimento de filmes biopoliméricos para liberação transdérmica permite a incorporação de um leque variado de fármacos, mantendo-os no sítio-alvo por suas propriedades de adesão, biodegradabilidade e inchamento ${ }^{3}$. O presente trabalho objetiva o preparo de filmes híbridos lipídicos-biopoliméricos, para encapsular o anestésico local lidocaína (LDC), visando a anestesia transdérmica. Os CLN são compostos por manteiga de Karité (lipídio sólido), óleo de amêndoas (lipídio líquido) e do detergente Koliphor $\AA$, incorporados em matrizes biopoliméricas (de alginato, quitosana e xantana).

\section{Resultados e Discussão}

Todas as formulações foram avaliadas por espalhamento de luz dinâmico (DLS) quanto ao tamanho $(\mathrm{nm})$, índice de polidispersividade (PDI) e potencial zeta $(\mathrm{mV})$. Após 120 dias a $25^{\circ} \mathrm{C}$, os valores de tamanho $<300 \mathrm{~nm}$, PDI <0,2 e potencial Zeta $>-25 \mathrm{mV}$, não sofreram variação significativa. As imagens por microscopia eletrônica de transmissão comprovaram a morfologia esférica das nanopartículas, tanto na presença quanto na ausência de lidocaína (2\%).
Tabela 1. Composição das formulações de CLN preparadas pelo método de emulsificação-ultrasonicação e eficiência de encapsulação de lidocaína (2\%), pelo método da ultrafiltração-centrifugação. Todas as formulações continham ainda $5 \%$ de Koliphor ${ }^{\circledR}$.

\begin{tabular}{lccc}
\hline Formulação & TL (\%) & LL (\%) & \%EE \\
\hline CLN1 & 9 & 20 & - \\
CLN1/LDC & 9 & 20 & $83,7 \pm 1,2$ \\
CLN2 & 5 & 30 & - \\
CLN2/LDC & 5 & 30 & $86,3 \pm 1,9$ \\
CLN3 & 9 & 30 & - \\
CLN3-LDC & 9 & 30 & $78,4 \pm 7,9$
\end{tabular}

$\mathrm{TL}=$ total de lipídios na formulação, $\mathrm{LL}=\%$ de lipídio líquido, \% $\mathrm{EE}=$ eficiência de encapsulação de LDC, $(n=3 ; \pm d p)$.

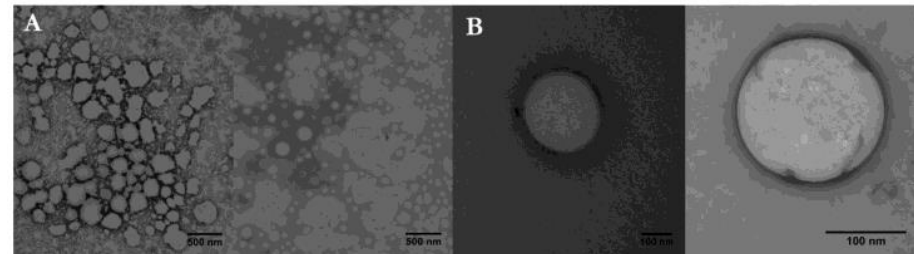

Figura 1. Imagens de MET de CLN2/LDC 2\% (à esquerda) e CLN2 (à direita). Magnificação de 60.000x (A) e 100.000X (B).

\section{Conclusões}

Foram preparados CLN compostos pelos lipídios naturais manteiga de Karité e óleo de amêndoas que encapsularam LDC (2\%). As formulações exibiram estabilidade físico-química por 120 dias $\left(25^{\circ} \mathrm{C}\right)$. A formulação CLN2 que encapsulou a maior quantidade de LDC $(86 \%)$ foi incorporada em matrizes de alginato, quitosana e xantana, processadas como filmes. Os materiais resultantes apresentaram flexibilidade $e$ elevada compatibilidade entre si e serão avaliados quanto à capacidade de absorção de água e liberação in vitro.

\section{Agradecimentos}

\section{FAPESP (\#2016/04158-6, \#14/14457-5)}

\footnotetext{
${ }^{1}$ Negi P. et al., Drug Deliv., 2014, 7544,1-17. ${ }^{2}$ Attama, A.A. et al., Rec. Adv Drug Del. Syst., 2012, 107-140. ${ }^{3}$ Poojari, R. \& Srivastava, R. Exp. Opin. Drug Deliv., 2013, 10, 1061-1076.
} 